\title{
Bactérias ácido lácticas suas características e importância: revisão
}

\author{
Lactic acid bacteria its characteristics and importance: review \\ Bacterias ácido lácticas sus características e importancia: revisión
}

Recebido: 28/08/2021 | Revisado: 02/09/2021 | Aceito: 06/09/2021 | Publicado: 07/09/2021

Thayná Thamires Freire
ORCID: https://orcid.org/0000-0003-2780-1580
Instituto Federal de Educação, Ciência e Tecnologia do Norte de Minas Gerais, Brasil
E-mail: thayna_sal@hotmail.com
Anna Lívia Tolentino e Silva
ORCID: https://orcid.org/0000-0001-7797-4071
E-mail: anna.l.tolentino@ @otmail.com
Bruna Karoline Oliveira Ferreira
Instituto Federal de Educação, Ciência e Tecnologia do Norte de Minas Gerais, Brasi
ORCID: https://orcid.org/0000-0003-0200-7284
E-mail: karolinebruna344@ gmail.com
Thiago Moreira dos Santos
Instituto Federal de Educação, Ciência e Tecnologia do Norte de Minas Gerais, Brasil
ORCID: https://orcid.org/0000-0001-8041-1149
Instituto Federal de Educação, Ciência e Tecnologia do Norte de Minas Gerais, Brasil
E-mail: thiagonso@gmail.com

\section{Resumo}

As bactérias ácido lácticas (BAL) são um grupo de micro-organismos que podem estar presentes em diversos meios ricos em nutrientes, representadas por cerca de 530 espécies e subespécies. Apresentam-se na forma de cocos ou bastonetes, são gram positivos, catalase negativa, não esporuladas e geralmente sem motilidade. Sua classificação em diferentes grupos se dá pela morfologia e fisiologia no uso de nutrientes, pressão osmótica e condições atmosféricas para seu crescimento. Sua identificação pode ser feita através de testes bioquímicos clássicos e métodos moleculares, mais atuais, eficientes e aceitos pela comunidade científica. As BAL podem ainda serem utilizadas como probióticos ao serem adicionadas aos alimentos para conferir benefícios a saúde dos consumidores. Elas conferem vantagens para a extensão da vida útil do alimento, através da diminuição do $\mathrm{pH}$, ou ainda, pela produção de peptídeos antagonistas contra outras bactérias. Modificam as propriedades sensoriais dos produtos, interferindo na intensidade do sabor e aroma dos alimentos fermentados. Nos animais de produção, as BAL além dos seus efeitos probióticos, exercem ação também sobre os índices zootécnicos, melhorando a sanidade e segurança alimentar aos produtos de origem animal. $\mathrm{O}$ objetivo do artigo é expor as características e a importância dessas bactérias e para isso foram reunidas cerca de 119 referências bibliográficas como fontes de pesquisa e aprendizado para o desenvolvimento do trabalho. Com isso, foi concluído que as BAL são de grande importância para a indústria, conferindo características sensoriais aos produtos, além de possuírem um papel importante para os animais, melhorando a sanidade e produção e, participação em saúde pública, através de seus efeitos probióticos.

Palavras-chave: Gram-positivo; Laticínios; Saúde pública.

\begin{abstract}
Lactic acid bacteria (LAB) is a group of microorganisms present in rich nutrients environment, with more than 530 species. They are cocos or rod forms, gram-positive and negative catalase, non-spore and without motility. Morphology and physiology classification are used to differentiation of LAB groups. The identifications can be made through biochemical tests and molecular techniques. These last ones are more efficient and accepted by scientific community. LAB can be used as probiotic when used in food, granting healthier product to consumers. Advantages on shelf-life are remarkable through $\mathrm{pH}$ reduction or antagonist peptides production. The sensorial characteristics are modified in fermented products, specially the flavor. In animal production, LAB can increase sanity and zootechnical indexes and also grant food safety in their derivative products. The objective of the article is to expose the characteristics and importance of these bacteria and for this, around 119 bibliographical references were gathered as sources of research and learning for the development of the work. Thus, it was concluded that BALs are of great importance to the industry, providing sensory characteristics to products, in addition to playing an important role for animals, improving health and production, and participation in public health, through their probiotic effects.
\end{abstract}

Keywords: Gram-positive; Dairy products; Public health. 


\begin{abstract}
Resumen
Las bacterias ácido lácticas (BAL) son un grupo de microorganismos que pueden estar presentes en diversos medios ricos en nutrientes, representados por cerca de 530 especies y subespecies. Se presentan en forma de cocos o bastoncillos, son gram positivo, catalasa negativa, no esporuladas y generalmente sin motilidad. Su clasificación en diferentes grupos se da por la morfología y fisiología en el uso de nutrientes, presión osmótica y condiciones atmosféricas para su crecimiento. Su identificación puede ser hecha a través de pruebas bioquímicas clásicas y métodos moleculares, más actuales, eficientes y aceptados por la comunidad científica. Las BAL pueden todavía ser utilizadas como probióticos al ser añadidas a los alimentos para dar beneficios a la salud de los consumidores. Ellas confieren ventajas para la extensión de la vida útil del alimento, a través de la disminución del pH, o, por la producción de péptidos antagonistas contra otras bacterias. Modifican las propiedades sensoriales de los productos, interfiriendo en la intensidad del sabor y aroma de los alimentos fermentados. En los animales de producción, las BAL además de sus efectos probióticos, ejercen acción también sobre los índices zootécnicos, mejorando la sanidad y seguridad alimentaria a los productos de origen animal. El objetivo del artículo es exponer las características e importancia de estas bacterias, y para ello se recogieron alrededor de 119 referencias bibliográficas como fuentes de investigación y aprendizaje para el desarrollo del trabajo. Así, se concluyó que los BAL son de gran importancia para la industria, aportando características sensoriales a los productos, además de jugar un papel importante para los animales, mejorando la salud y la producción, y participación en la salud pública, a través de sus efectos probióticos.
\end{abstract}

Palabras clave: Gram positivas; Productos lácteos; Salud pública.

\title{
1. Introdução
}

As bactérias ácido láticas (BAL) pertencem a um grupo de diferentes bactérias largamente encontradas na natureza. São micro-organismos gram positivo, catalase negativo, podendo apresentar-se na forma de cocos ou bacilos. Podem ser encontradas em meios ricos em nutrientes, tais como trato gastrointestinal, urogenital, em alimentos fermentados como leite e derivados, carne e grãos, além de esgotos e silagem. São bastante empregadas na produção de alimentos, como leites fermentados, iogurtes e queijos, bem como no processamento de carnes e bebidas alcoólicas. As BAL contribuem para a extensão da vida útil do alimento, através da diminuição do pH, ou ainda, pela produção de peptídeos antagonistas a outras bactérias, podendo também modificar as propriedades sensoriais dos produtos, interferindo na intensidade do sabor e aroma dos alimentos fermentados.

Nos últimos anos, com o aumento da procura por alimentos seguros, que não recorram à adição excessiva de conservantes químicos, os consumidores vêm procurando alimentos mais adequados às suas necessidades e muitas vezes optando por aqueles que, além de seguros, são considerados benéficos para a saúde. Determinadas BAL podem ser utilizadas com essa finalidade, agindo como probióticos ao serem adicionadas aos alimentos para conferir benefícios à saúde dos consumidores. Nos animais de produção, as BAL além dos seus efeitos probióticos, exercem ação também sobre os índices zootécnicos destes, possuem ainda efeito imunomodelador e podem ser utilizados como alternativas aos antibióticos promovem aumento da proteção das mucosas, além, de virem sendo buscadas melhoras no desempenho reprodutivo dos animais. O objetivo da elaboração de uma revisão de literatura sobre o isolamento a caracterização e a identificação de bactérias ácido láticas, bem como sua importância para a indústria, pecuária e saúde pública.

\section{Metodologia}

O presente artigo trata-se de uma revisão de literatura sobre as bactérias ácido lácticas, abordando as suas características e a sua importância. Para a realização deste, foram reunidas cerca de 119 referências bibliográficas encontradas nas bases de dados Google, Scielo e Google Acadêmico, utilizando as palavras-chave "BAL”, "bactérias ácido lácticas", “microrganismo", “alimentos" e "saúde pública", além dos livros, revistas, legislações e sites especializados. Aqueles que não apresentavam as informações buscadas nos objetivos da pesquisa, foram descartados. O intuito inicial era selecionar somente trabalhos feitos recentemente, porém, foram selecionados também trabalhos mais antigos, devido à importância das informações contidas nos mesmos. 


\section{Resultados e Discussão}

\subsection{As Bactérias Ácido Lácticas}

As bactérias ácidas lácticas (BAL) foram obtidas inicialmente a partir de uma amostra de leite por Joseph Lister em 1873, sendo classificadas como Bacteriumlactis (Salminen \& Wrigth, 1993). Em 1901 Beijerinck começou a descrever estes micro-organismos, sendo Orla-Jensen em 1919 o responsável por dividir o gênero em dois grupos, baseando-se nas suas características fenotípicas, a temperatura ótima de crescimento e a forma de fermentação. Este autor, com uma razoável precisão, usou as características morfológicas, metabólicas e fisiológicas destas bactérias como critérios para estabelecer a sua diferenciação taxonômica (Inês et al., 2008).

São descritas como cocos ou bastonetes com células simples, duplas ou tétrades podendo ainda formar pequenas ou grandes cadeias. Elas são gram-positivas, catalase negativa, não esporuladas, geralmente sem motilidade, com exceção de Lactobacillus agilis, Lactobacillus ghanensis e Lactobacillus capillatus, não reduzem nitrato a nitrito, sendo também desprovidas de citocromo e ácido tolerantes (Nielsen et al., 2007; Chao et al., 2008). Quanto à capacidade de assimilar oxigênio podem ser anaeróbias, anaeróbias facultativas, aeróbias e microaerófilas. Segundo Lehninger et.al. (2011), as BAL são as únicas desprovidas de catalase (enzima que degrada o peróxido de hidrogênio $\left(\mathrm{H}_{2} \mathrm{O}_{2}\right)$ ) que conseguem crescer em condições aeróbias. A incapacidade das BAL em degradar este composto, deve-se ao fato de não sintetizarem grupos porfirínicos, como exemplo o heme. Apesar de serem incapazes de sintetizar adenosina trifosfato (ATP) por meios respiratórios, as BAL não têm seu crescimento afetado pela presença ou ausência de ar. Elas podem ser classificadas como mesófilas ou termófilas, conforme a temperatura ótima para crescimento, entre $30{ }^{\circ} \mathrm{C}$ a $37{ }^{\circ} \mathrm{C}$ e entre $42^{\circ} \mathrm{C}$ a $50^{\circ} \mathrm{C}$, respectivamente, além do fato de a maioria ser inativada a temperaturas superiores a $70^{\circ} \mathrm{C}$ (Sybesma et al., 2006).

Possuem capacidade de crescer em $\mathrm{pH}$ de 3,8, produzem grande número de enzimas glicolíticas, lipolíticas e proteolíticas, que transformam os nutrientes em compostos com propriedades sensoriais desejáveis (LIMA et al., 2009). Além de enzimas, as BAL produzem vários fatores antimicrobianos, incluindo ácidos orgânicos, bacteriocinas, diacetil e acetaldeído, que atuam favoravelmente nos produtos alimentares, fazendo parte dos micro-organismos capazes de exercer efeitos benéficos ao hospedeiro (Forsythe, 2002; Lima et al., 2009).

Algumas BAL podem ainda ser usadas por secretarem exopolissacarídeos, influenciando a textura dos alimentos quando tal fato for desejável (Chammas et al., 2006). Os exopolissacarídeos microbianos (EPS) sintetizados pelas BAL, desempenham um papel importante na produção de lácteos fermentados. Estes polímeros aumentam a viscosidade do leite, diminuem a susceptibilidade à sinérese, contribuem para a textura, sensação na boca, para a percepção do sabor e para a estabilidade do produto final (Cerning et al., 1992).

\subsection{Isolamento, Caracterização e Identificação}

A identificação de BAL pode ser realizada mediante o crescimento em meios de cultura seletivos. Para isso, há uma série de meios de cultura disponíveis; porém, os mais utilizados são o ágar M17 e o ágar Rogosa acidificado ou o ágar MRS, para isolamento de bactérias com morfologia de cocos e bacilos, respectivamente (Hassan \& Franck, 2001; Carvalho, 2007). Estas são incubadas em condições de anaerobiose, a 37 ${ }^{\circ} \mathrm{C}$, durante 48 horas (Embrapa, 2009; Resende, 2011).

A classificação fenotípica dos isolados considerados puros é feita de acordo com as suas características fisiológicas e bioquímicas. Os diferentes isolados são selecionados em primeira mão em função da sua coloração de Gram e do teste de Catalase. São realizados também os testes: microscopia para avaliar a forma, teste da oxidase, capacidade de crescimento a diferentes temperaturas e concentrações de $\mathrm{NaCl}$ e de $\mathrm{pH}$, produção de $\mathrm{CO}_{2}$ a partir da glicose, atividade antimicrobiana e, por fim, a resistência das bactérias lácticas isoladas a diferentes antibióticos (Lerayer, 2009). 
Entretanto essa metodologia não permite a distinção exata entre espécies ou linhagens, pois geralmente requer a determinação de propriedades bacterianas além daquelas abordadas pelos testes fermentativos (Tannock et al., 1999).

A aplicação de técnicas de biologia molecular, em particular aquelas que envolvem a amplificação de genes específicos por intermédio de reação de polimerização em cadeia (Polymerase Chain Reaction - PCR), tem se destacado nos últimos anos. As variações observadas na sequiência e comprimento da região espaçadora entre as subunidades ribossomais 16S-23S do DNA ribossomal (rDNA) são utilizadas para identificação de espécies de micro-organismos (Gurttler \& Stanisich, 1996). Esta região do DNA é bastante variável entre as espécies de micro-organismos, porém, bastante conservada em microorganismos da mesma espécie, sendo então, utilizada em pesquisas de identificação microbiana, no nível molecular (Tannock et al., 1999).

Um método específico e reprodutível para a identificação de espécies e linhagens de BAL seria a amplificação por PCR da região do 16S-23S e posterior restrição com endonucleases específicas (AmplifiedRibosomal DNA RestrictionAnalysis - ARDRA). Este método tem se mostrado mais rápido, fácil e preciso para identificação dessas bactérias em comparação com as metodologias baseadas no perfil de assimilação de carboidratos (Moreira et al., 2005).

Greppi et al. (2015), fizeram um monitoramento da microbiologia de enchidos, incluindo o salame, através de RTPCR obtida do RNA extraído, com essa técnica, conseguiram detectar diversas espécies de BALs metabolicamente ativas que se desenvolveram durante o amadurecimento do salame.

Tremonte et al. (2017), realizaram um estudo para detectar diferentes microambientes e Lactobacillus em ventricina, que é uma linguiça fermentada tradicional da Itália. O experimento foi realizado através da técnica de PCR e análise de sequência da região V1-V3 do gene 16S rRNA e, com isso, foi encontrada em destaque a presença de Lactobacillus sakei e Lactobacillus plantarum.

Bostan et al. (2017), fizeram um estudo para identificar e caracterizar BALs isoladas em iogurte de cone tradicional através de RT-PCR e notaram a presença destacada do Lactobacillus plantarum, além de uma série de outros gêneros de BALs. Os resultados encontrados pelos autores, indicam que o iogurte estudado possui uma microflora mista.

Outra metodologia amplamente utilizada em estudos filogenéticos, taxonômicos e ecológicos para a identificação de espécies bacterianas é o sequenciamento do gene 16S do RNA ribossomal (rRNA). Esse gene é universalmente distribuído e pouco alterado ao longo do processo de evolução das espécies, tornando-o um alvo ideal para estudos de identificação (Madigan et al., 2010). A identificação das bactérias lácticas pode ser feita utilizando-se a análise de restrição e confirmada através do sequenciamento com maior fidedignidade.

Novas metodologias, exames e técnicas relacionados a biologia celular vêm se desenvolvendo ao longo dos anos. Através disso, originou-se a matrix assisted laser desorption/ionization time-of-flight mass espectrometry (MALDI-TOF-MS), também conhecida como dessorção/ionização a laser observada por uma matriz acoplada a espectrometria de massa por tempo de voo. É uma técnica com base em conceitos proteômicos e tem capacidade de chegar a resultados altamente precisos em questão de pouquíssimos minutos (Pebmed, 2020).

Nacef et al. (2016) utilizaram essa técnica para a identificação de bactéria ácido lática em queijo francês. Ao encontrar diversas cepas de BALs de diferentes gêneros no alimento em pouco tempo, concluiu que, a identificação microbiana com base na técnica MALDI-TOF-MS é uma abordagem molecular que preenche espaço entre a confiabilidade dos resultados dos testes produzidos em um sistema fenotípico com base bioquímica e um sistema de identificação genotípica, além de ser um método mais econômico, robusto, evolutivo, confiável e adequado para o gerenciamento de dados.

Angelakis et al. (2011), realizaram um estudo para identificar bactérias em iogurte e probióticos através da técnica de MALDI-TOF-MS e, assim como Nacef e seus colaboradores, concluiu que a técnica usada é bastante precisa e útil para a identificação de BALs. 
Dec et al. (2016), realizaram um estudo com base na técnica de MADI-TOF-MS e em outra técnica denominada 16SARDRA. Concluíram que as duas técnicas são valiosas para a identificação de BALs, principalmente do gênero Lactobacillus, que além de identificar a bactéria, ainda ajudam a determinar as relações entre as cepas.

\subsection{Probióticos}

O pesquisador Ellie Metchnikoff foi considerado o precursor do conceito probióticos. Em seu livro de 1907, "O prolongamento da vida", propôs que as bactérias tinham um papel para a saúde de adultos. Teoria levantada após se observar que os camponeses búlgaros, que consumiam leites fermentados possuíam uma maior longevidade. Metchnikoff acreditava que o corpo era autointoxicado por toxinas produzidas por micro-organismos proteolíticos no intestino. Sua hipótese era de que o envelhecimento poderia ser evitado, modificando a microbiota intestinal com a utilização de "micróbios úteis" (Mizock, 2015).

A Organização Mundial de Saúde (OMS) define probióticos como "organismos vivos que, quando administrados em quantidades adequadas, conferem benefícios à saúde do hospedeiro" (Fao/Who, 2002). A Agência Nacional de Vigilância Sanitária (Anvisa, 2002) estipula que a quantidade mínima viável para os probióticos atuarem de maneira benéfica para o hospedeiro deve estar situada na faixa de $10^{8}$ a $10^{9}$ Unidades Formadoras de Colônias (UFC) na recomendação diária do produto pronto para o consumo.

A fabricação de produtos contendo bactérias probióticas tem como base a seleção desses micro-organismos de acordo com a estabilidade frente ao ácido e à bile; o gênero ao qual pertence a bactéria que deve preferencialmente ser de origem humana; a capacidade de sobreviver no trato gastrintestinal humano e a capacidade de produzir compostos antimicrobianos no intestino. Também necessitam, de acordo com Food and DrugAdministration (FDA), serem geralmente reconhecidas como seguras - em tradução livre do termo Generally Recognized as Safe (GRAS), ou seja, não ser patogênicas e não causar doenças tais como endocardite, além da ausência de genes determinantes da transmissão da resistência a antimicrobianos (Collins et al., 1998; Lee et al., 1999; Saarela et al., 2000; Nagpal et al., 2012).

O status "Presunção de Segurança Qualificada" (QPS) é certificado pela Autoridade de Segurança Alimentar Europeia (EFSA) aos micro-organismos que foram submetidos a um sistema de avaliação para segurança pré-comercialização, onde é estabelecido a identidade, a possível patogenicidade e o uso final do micro-organismo. Atualmente, o status QPS é conferido a 38 BAL: três espécies de Pediococcus (Pediococcus acidilactici, Pediococcus dextrinicus e Pediococcus pentosaceus) e 35 espécies de Lactobacillus (Efsa, 2015).

Pugliesi et al., (2014) destacam os efeitos benéficos de culturas probióticas no controle de infecções intestinais, o estímulo da motilidade intestinal com consequente alívio da constipação intestinal, a melhor absorção de alguns nutrientes, melhor utilização de lactose e alívio dos sintomas de intolerância a esse açúcar. Os autores citam também a diminuição dos níveis de colesterol, e o estímulo do sistema imunológico através da incitação da produção de anticorpos e da atividade fagocítica contra patógenos intestinais, além da exclusão competitiva e produção de compostos antimicrobianos.

Espeche et al., (2012) isolou BAL a partir do leite cru, com o objetivo de selecionar cepas potencialmente benéficas na prevenção da mastite, uma vez que, o tratamento desta doença é com base no uso de antibióticos que nem sempre são eficazes e podem deixar resíduos no leite. Foram isoladas 117 BAL, que tinham como características benéficas, a produção de substâncias inibitórias e produção de EPS. Foram estudados os fatores de virulência e a resistência aos antibióticos para a avaliação da segurança das cepas. Nove linhagens isoladas inibiram três bactérias indicadoras de mastite. Já Bouchard, et al. (2015) isolou BAL autóctones da microbiota mamária de vacas, que continham benefícios que poderiam ser usados da prevenção e tratamento da mastite. Três cepas, Lactobacillus brevis 1595 e 1597 e Lactobacillus plantarum 1610, foram selecionadas para colonizar a glândula mamária, precisando, ainda, investigações sobre seu efeito em relação aos principais patógenos da mastite e às celulas epiteliais mamárias de bovinos. 
O uso de probióticos para a saúde humana e animal está aumentando continuamente. Os probióticos usados em humanos geralmente vêm de alimentos lácteos, enquanto as fontes de probióticos usados em animais são muitas vezes os próprios animais tratos digestivos. Fontes alternativas de probióticos, como produtos alimentícios fermentados não lácteos, apresentam uma vantagem na pesquisa de novas cepas probióticas. Cada vez mais, essas fontes de probióticos estão sendo selecionadas para uso em pessoas que são intolerantes à lactose. Essas fontes são alimentos e bebidas fermentados não lácteos e não fermentados, como por exemplo, alimentos como frutas e vegetais frescos (Sornplang \& Piyadeatssontorn, 2016).

A seleção de probióticos de diferentes fontes envolvem a triagem de não patogênicos micróbios seguida por uma avaliação das propriedades básicas, incluindo tolerância a ácido e bile, a capacidade de aderir a células epiteliais do intestino, uma capacidade de combater patógenos no trato gastrointestinal e a propriedade de aumento de segurança de uma incapacidade de transferir quaisquer genes de resistência a antibióticos a outras bactérias (Sornplang \& Piyadeatssontorn, 2016).

Probióticos selecionados isolados de fontes intestinais em humanos e animais são identificados usando métodos moleculares por dois métodos principais: métodos baseados e independentes da cultura. O método independente de cultura é considerado como técnicas alternativas para investigar a grande proporção de bactérias cultivadas e não cultivadas no trato gastrointestinal (Sornplang \& Piyadeatssontorn, 2016).

Os probióticos podem exercer seus efeitos benéficos no organismo partir de vários mecanismos de ação sendo estes os mais importantes: modulação da imunidade, inibição de patógenos e restabelecimento da homeostase microbiana e proteção da barreira epitelial (Oelschlaeger, 2010).

Os probióticos, juntamente com suas moléculas efetoras, têm demonstrado conferir atividades imunorregulatórias, antiangiogênicas, antialérgicas, anticolite e antidérmicas, entre outras. A pesquisa de probióticos representa um campo em rápida evolução que se expandiu do conforto digestivo tradicional para diversos benefícios para a saúde, otimizando assim, o período de suplementação, seleção de cepas competentes, e decifrando a influência de fatores do hospedeiro podem aumentar a eficiência biológica (Patel et al., 2015).

\subsection{Modulação da imunidade}

A imunidade é a capacidade do corpo de neutralizar invasões patogênicas. A falta disso compromete a saúde e a sobrevivência, tornando sua retenção e escalonamento de extrema importância (Patel, et al., 2015). O estímulo da imunidade específica e não específica pode ser um possível mecanismo dos probióticos para proteger o hospedeiro contra doenças intestinais. Este mecanismo não está bem documentado, porém acredita-se que os componentes específicos da parede celular ou as camadas celulares podem atuar como adjuvantes e aumentar a resposta imune humoral (Giorgetti et al., 2015), modulando o aumento do número e atividade de células fagocíticas, (Ferreira; Astolfi-Ferreira, 2006) consequentemente a produção de anticorpos (Busanello, 2012).

Coppola e Turnes (2004), abordaram as principais aplicações dos probióticos dando ênfase nas informações recentes sobre suas propriedades de modular a resposta imune e, concluíram que, vários probióticos têm, além de sua atividade como promotores de crescimento e reguladores da microbiota das mucosas, efeito imunomodulador, embora a forma de ação ainda era pouco conhecida na época de realização desse estudo.

As evidências acumuladas sobre os benefícios decorrentes do uso dos probióticos justificam o aprofundamento dos estudos sobre seu modo de ação, a fim de otimizar sua utilização como profiláticos, promotores de crescimento e imunomoduladores (Coppola \& Turnes, 2004).

Bittencourt (2006) avaliou os efeitos da utilização de probióticos sobre parâmetros da resposta imune, hematológicos e de desempenho de 1200 frangos de corte criados até 42 dias de idade em um delineamento inteiramente casualizado, com 3 tratamentos (antibiótico, probiótico e controle) e 10 repetições. Em conclusão, foi notório observar resposta positiva do 
probiótico com relação ao antibiótico, comparando a produção de anticorpos em resposta a vacina de Newcastle, porém, não foi diferenciado do grupo controle. Já os valores hematológicos se encontraram dentro na normalidade.

Ferreira (2010) avaliou a suplementação com probiótico e vacinação antirrábica na resposta imune humoral em 34 bovinos de 15 meses de idade, divididos em dois grupos que foram vacinadas no dia zero. Um dos grupos recebeu uma mistura mineral com probiótico, enquanto o outro recebeu apenas a mistura. $\mathrm{O}$ sangue dos animais foi colhido nos dias 0,75 e 150 após a aplicação da vacina, para determinar títulos de anticorpos antirrábicos. Em resultados, concluiu que a vacina antirrábica é eficiente para a produção de soroconversão, além de manter os títulos de anticorpos em bovinos primovacinados. A ingestão do probiótico não interferiu na resposta imune humoral antirrábica.

Almeida et al. (2012), assim como Ferreira (2010), estudaram os efeitos dos probióticos na resposta imune humoral juntamente com a aplicação de vacina antirrábica em 40 bovinos de 12 meses de idade, divididos em dois grupos. Um grupo recebeu somente 70 gramas de suplemento mineral/animal/dia e outro grupo recebeu 70 gramas de suplemento mineral/animal/dia adicionado de 4 gramas de probiótico/animal. Em análise, concluíram que a vacina antirrábica utilizada teve eficiência em produzir e manter a soroconvesão nos bovinos primovacinados contra a raiva por 150 dias e a administração de probiótico não interferiu na resposta imune humoral antirrábica.

Patel et al. (2015), analisaram os probióticos na valorização da imunidade inata em diversos animais, incluindo peixes, aves, ratos, porcos e macacos, além do ser humano e, concluíram que, os probióticos se estabeleceram como um segmento onipresente do domínio alimentar funcional atual, sendo capazes também, de aumentar a produção de diversos mediadores pró e anti-inflamatórios.

Oshiro (2015) desenvolveu um estudo para avaliar o desempenho zootécnico, a composição corporal, o perfil hematológico, a resposta imune inata e a taxa de sobrevivência frente à infecção experimental com Aeromonas hydrophila e confirmar a presença do probiótico no intestino de tilápia-do-nilo, Oreochromis niloticus, alimentados com adição de prebióticos e probióticos na ração. Em análise, notaram que a inclusão dos probióticos e prebiótico não afetou as condições imunológicas, hematológicas, de desempenho zootécnico e de composição corporal dos animais testados. Foi possível recuperar as bactérias probióticas (Bacillus cereus e B. subtilis) no trato intestinal das tilápia-do-nilo.

Teixeira (2017) em uma pesquisa sobre o efeito imunomodulador e carrapaticida de micro-organismos probióticos em bovinos da raça Girolando, submeteu 30 animais a diferentes tipos de tratamento, dentre eles o uso de probióticos isoladamente e associados a vacina. Os animais pertencentes aos grupos vacinados e tratados com preparações probióticas, apresentaram níveis superiores de imunoglobulina $\mathrm{G}(\mathrm{IgG})$, mas os animais que receberam apenas preparações probióticas tiveram seus valores aumentados quando comparados, por um período mais prolongado, aos animais que foram vacinados.

Deng et al. (2016), realizou um trabalho, sobre a utilização de probióticos via intravaginal em vacas leiteiras, onde foi observadoo aumento da IgG total e o teor de proteína no leite em relação ao grupo não tratado. Além disso, vacas tratadas com o probiótico exibiram maior produção de leite e melhor eficiência alimentar. Resultados são especulados como relacionados à redução de infecções uterinas e translocação de endotoxinas, não sendo elucidado o mecanismo pelos quais as BAL administradas via intravaginal influenciam a produção de leite e estado metabólico de vacas leiteiras.

Rodríguez et al., (2011) isolou BAL do trato reprodutivo de vacas de leite e corte durante o estágio progesterônico do ciclo estral, com o intuito de elucidar a presença de cepas com alto potencial de emprego probiótico. Do total de cepas identificadas, $83 \%$ corresponderam aos lactobacilos, sendo que a maioria das cepas pertencia ao grupo facultativo heterofermentativo, destacando a L. plantarum como a espécie mais frequente. 


\subsection{Inibição de patógenos e restabelecimento da homeostase microbiana}

Além da imensa aplicabilidade como probióticos e como bioconservantes de alimentos, as bacteriocinas atuam como alternativa aos antibióticos convencionais no tratamento de doenças associadas à patógenos microbianos (Ogaki et. al., 2015).

As bacteriocinas são tradicionalmente consideradas como peptídeos biologicamente ativos que têm propriedades bactericidas contra outras espécies intimamente relacionadas à cepa produtora. Recentemente este conceito foi modificado, devido as ações que foram encontradas de bactericidas contra cepas distanciadas filogeneticamente da cepa produtora (Sablon, 2000).

As bacteriocinas são consideradas peptídeos antimicrobianos sintetizados nos ribossomos, tendo descrita uma imensa variedade de bacteriocinas, as quais diferem entre si quanto a composição de aminoácidos, biossíntese, modo de ação e transporte. Em alimentos, as bacteriocinas podem ser encontradas naturalmente como produtos da microbiota normal ou introduzida (Ogaki et al., 2015)

Bacteriocinas são peptídeos com propriedades bacteriostáticas sobre diversas espécies de micro-organismos. Podem ser divididas em bacteriocinas com espectro inibitório limitado, afetando apenas espécies geneticamente próximas e as com espectro inibitório amplo, podendo afetar diversas espécies de micro-organismos gram-positivos (Schneider, 2016). A produção de bacteriocinas é codoficada por plasmídios, assim como é plasmidial a resistência à antibióticos (Franco \& Landgraf, 2008).

As bacteriocinas mais estudadas são a Nisina, a Pediocina, e a Sakacina produzidas por Lactococcuslactis, Pediococcusacidilactici e Lactobacillus sakei, o estudo da aplicação de culturas produtoras de bacteriocinas com o intuito de realizar a bioconservação tem sido realizada principalmente em produtos lácteos e cárneos fermentados. A Nisina é a única cujo uso em alimentos é autorizado pela FDA. É utilizada na preservação de alimentos em vários países (Franco \& Landgraf, 2008).

Costa (2016) realizou um trabalho onde isolou, a partir de queijo Minas frescal, BALs produtoras de bacteriocinas com potencial para utilização em sistemas de bioconservação de produtos lácteos. Em conclusão, observou que foi possível isolar, a partir de QMF culturas produtoras de bacteriocinas com atividade inibitória frente a Listeria monocytogenes $e$ Staphylococcus aureus. Observou também que as quatro BALs com melhor atividade inibitória frente aos patógenos avaliados (QMF 4, QMF 6, QMF 11 e QMF 18) foram identificadas através de sequenciamento do gene 16s rRNA como Lactococcus lactis. A cepa selecionada para os testes de co-inoculação em leite pasteurizado $\left(8^{\circ} \mathrm{C}\right.$ por 10 dias), QMF 11, inibiu a multiplicação de Listeria monocytogenes já a partir do $4^{\circ}$ dia de incubação (Listeria monocytogenes + BAL QMF11), enquanto a inibição de Staphylococcus aureus ocorreu apenas a partir do $6^{\circ}$ dia de incubação (S. aureus + BAL QMF11). Apesar de inibir significativamente a multiplicação de Staphylococcus aureus, Lactococcus lactis QMF 11 foi mais eficiente em inibir Listeria monocytogenes. O Lactococcus lactis QMF 11, produtor de bacteriocinas, apresenta potencial para utilização em sistemas de bioconservação de produtos lácteos.

Laranja (2016) avaliou a atividade antimicrobiana da nisina em presunto cozido sobre Listeria monocytogenes e BALs e notou que a adição de $12,5 \mathrm{mg} / \mathrm{kg}$ de nisina ao presunto cozido fatiado, armazenado a $8{ }^{\circ} \mathrm{C}$, foi bastante eficaz para o controle da população de BAL, mantendo diferença significativa até o décimo dia comparado com o controle. Entretanto, essa concentração não foi eficaz e suficiente para inibição de L. monocytogenes em presunto. Pôde-se constata que diferentes cepas de L. monocytogenes apresentaram perfis de sensibilidade diferentes e que a união destas em um pool apresentou maior resistência, não relacionada a presença de uma cepa específica selvagem. Foi demonstrado que uma concentração de $32 \mathrm{mg} / \mathrm{kg}$ de nisina apresentou ação inibitória sobre um pool de L. monocytogenes e sobre uma cepa de L. monocyogenes ATCC 7644, por 10 dias, em presunto cozido com salmoura a $36 \%(\mathrm{~m} / \mathrm{m})$ do peso da carne. 
Heredia-Castro et al. (2017) realizaram uma revisão sobre o as bacteriocinas de BALs, avaliando o mecanismo de ação e a atividade microbiana contra patógenos em queijos. Concluíram que o uso de bacteriocinas ou BALs que produzem bacteriocinas em queijos poderiam ser viáveis para uso no controle sanitário da indústria de queijo.

Souza (2017), avaliou a ação antimicrobiana de bacteriocina produzida por Lactobacillus sakei e concluiu que a bacteriocina tem ação potencial para uso como conservante natural em alimentos, como queijos, reduzindo a contagem de estafilococos coagulase positiva em aproximadamente 78,85\% da contaminação inicial. A bacteriocina também apresentou estabilidade a elevadas temperaturas e $\mathrm{pH}$ próximo ao neutro, mostrando que pode ser utilizada em alimentos que recebam tratamento térmico.

Santos et al. (2019) fizeram uma caracterização parcial probiótica e molecular de BALs isoladas de queijo de coalho fabricado no Pernambuco e perceberam que a caracterização probiótica é extremamente necessária, pois não são todas as BALs que apresentam essas características, por isso os testes são essenciais para a segurança do consumidor. No trabalho, foram isoladas 11 bactérias, dessas, apenas duas foram eficientes para a maioria dos testes demonstrando o seu potencial probiótico. A identificação como pertencente ao gênero Enterococcus acentua sua caracterização como um probiótico. Com isso, perceberam que bactérias isoladas do queijo de coalho pernambucano representam importante fonte de microrganismos benéficos para a tecnologia de alimentos e saúde humana e animal.

Antônio e Borelli (2020) realizaram uma revisão sobre a importância das BALs na segurança e na qualidade dos queijos minas artesanais e concluíram que a presença das mesmas nos queijos tem importância não só no processo de fermentação e transformação do leite no queijo, mas também é essencial para o desenvolvimento das características organolépticas do produto, como o aroma, textura e sabor. Além disso, a atuação delas como bioconservantes tem sido amplamente estudada e comprovada através de pesquisas, demonstrando a produção de substâncias antimicrobianas e sua ação antagonista sobre patógenos, que possam estar presentes em queijos artesanais, durante o processo de maturação, melhorando a qualidade microbiológica e a segurança alimentar do produto.

Prado e colaboradores (2000), em estudo sobre a atividade antimicrobiana de bactérias lácticas de embutidos curados frente a Listeria monocytogenes, observou atividade antimicrobiana indireta de cepas de bactérias lácticas, insinuando que estas produziram substâncias semelhantes a bacteriocinas. Furtado et al. (2015) em estudo observou redução de mais de 6 log UFC/mL nas contagens de L. monocytogenes com adição de nisina em queijo tipo Minas frescal de leite de cabra por 10 dias, a $8-10^{\circ} \mathrm{C}$. Arqués et al. (2011) observou que nisina e reuterina produzida por Lactobacillus reuteri apresentaram atividade antilisterial e antiestafilocócica em leite desnatado pasteurizado por Ultra High Temperature (UHT) e armazenado em $4^{\circ} \mathrm{C}$ e $8^{\circ} \mathrm{C}$.

Outros compostos de ação antimicrobiana são os ácidos orgânicos, bem como os ácidos lático e acético, que são produtos decorrentes do processo fermentativo realizado pelos probióticos. Desta forma, é gerado um efeito antimicrobiano dos ácidos. Isso está relacionado a fatores, tais como: queda do $\mathrm{pH}$, o que irá causar uma redução tanto no pH do meio quanto no pH intracelular, pois a entrada de ácido através da membrana celular irá alterar o metabolismo da célula, resultando em um aumento do consumo de ATP celular. A redução no pH, além de inibir o crescimento de patógenos, favorece o desenvolvimento de bactérias probióticas, principalmente Lactobacillus spp., que são altamente adaptados a ambientes ácidos (Garcia, 2006; Lebeer et al., 2008)

Em estudo feito por Zabot (2016), foi analisado a eficácia de compostos clorados e ácidos orgânicos na redução da contaminação de carne de frango por Salmonella spp., mesófilos e enterobactérias. Neste trabalho foi possível observar que o ácido lático inibiu o crescimento bacteriano dos micro-organismos que foram testados. Rocha (2016), em estudo sobre o uso de butirato de sódio protegido em rações de frango de corte, observou que este ácido em condições semelhantes de manejo, ambiência e desafio sanitário pode substitui antibiótico promotor de crescimento. 
A infecção por Clostridium difficile (CDI) é uma doença muito comum na suinocultura, mas mesmo assim, ainda há falta de medidas preventivas. O estudo de Arruda et al., (2016), avaliou o uso de Lactobacillus spp. e uma cepa não-toxigênica de $C$. difficile (NTCD) como opções de microrganismos ingeridos para tentar prevenir o desenvolvimento de CDI em leitões. No presente estudo, de início, o probiótico foi ofertado como dose única, na intenção de imitar uma possível administração do mesmo no dia-a-dia, porém, essa dose não foi eficiente para ter melhorias, com isso, houve uma outra administração do probiótico e o resultado foi bastante favorável. Os autores mostraram que a administração de NTCD reduziu a existência de leitões toxina-positivos, diminuiu o edema mesocolônico e as lesões microscópicas, indicando um benefício para a administração de NTCD como opção de prevenção para CDI em leitões. O estudo também afirma que, uma única admisnistração de Lactobacillus spp. não é suficiente para previnir o desenvolvimento de doenças.

\subsection{Proteção epitelial}

As principais propriedades utilizadas para a proteção do epitélio intestinal são a competição por nutrientes e/ou competição entre linhagens patogênicas e micro-organismos probióticos pelos mesmos sítios de adesão, além da indução da síntese de defensinas e muco (Oelschlaeger, 2010). A exclusão competitiva, como o próprio nome diz, ocorre pela competição entre os micro-organismos probióticos e os patógenos por sítios de adesão na mucosa, a exemplo da competição entre Escherichia coli, e Lactobacillus spp. por sítios de receptores de oligossacarídeos. Neste caso, são produzidas algumas proteínas chamadas de adesinas que permitem a adesão de Lactobacillus spp., impedindo ou diminuindo a área disponível para E. coli com consequente queda na sua população no intestino (Lebeer et al., 2008).

Além disso, probióticos promovem aumento da proteção das mucosas contra patógenos, pois estimulam a produção de mucinas e defensinas. No primeiro caso, há melhora da expressão gênica nas células caliciformes, responsáveis pela produção do muco que reveste o trato gastrointestinal, resultando no aumento da camada mucosa que auxilia na proteção contra translocação e na eliminação de patógenos (Lebeer et al., 2010). A produção de defensinas, decorre da ligação com as células de Paneth, nas quais os probióticos estimulam a expressão de RNA mensageiro (mRNA) da $\beta$-defensina, resultando na produção da substância (Lebeer et al., 2010; Isli, 2013).

Estudos em animais sugerem que perturbações de comportamento, como o estresse e depressão, podem alterar a composição e a atividade metabólica da microbiota intestinal, por consequência, podem afetar o comportamento emocional e sistemas cerebrais relacionados. Apesar do interesse emergente na comunicação cérebro-intestino e seu possível papel nos transtornos do humor, há poucos estudos que abordam aspectos centrais e periféricos destas doenças. Uma pesquisa relatou a redução nos comportamentos de ansiedade a partir da ingestão de Bifidobacteriumlactis HN019, dando evidências encorajadoras para apoiar a proposta de que este probiótico pode apresentar propriedades ansiolíticas. No entanto, os resultados preliminares tornam necessárias mais investigações sobre parâmetros bioquímicos e mecanismos envolvidos nesta ação (Silva, 2017).

Atualmente, existem vários estudos investigando os reais benefícios de alimentos fermentados e probióticos à saúde humana (Ivey et al., 2015). Na diarreia, os efeitos dos probióticos ainda não estão totalmente elucidados, no entanto, existem pesquisas que relatam efeitos benéficos de probióticos sobre alguns tipos de diarreia (Dietrich et al., 2014). Bons resultados foram obtidos no tratamento de diarreia com o uso de cepas de Lactobacillus rhamnosus GG (Pant et al., 2011; Nixon et al., 2012; Zhang et al., 2013). O uso de probióticos na diarreia associada a antibióticos surge no sentido de restabelecer o equilíbrio da microbiota intestinal e reforçar a estabilidade da barreira quando do uso dos antibióticos, a fim de prevenir a integridade da barreira intestinal e o surgimento da diarreia (Mizock, 2015). 


\subsection{Câncer do cólon}

Ainda que o mecanismo pelo qual os probióticos tenham ação no câncer do cólon não tenha sido esclarecido, algumas hipóteses são relatadas: supressão do carcinógeno por diminuição do pH intestinal, variando a atividade da microbiota e a solubilidade da bile; variações do tempo de trânsito intestinal, retirando substâncias mutagênicas mais eficientemente; estimulação do sistema imune; supressão do carninógeno/procarcinógeno por ligação, remoção ou bloqueio; supressão de bactérias com atividade enzimática (Pimentel, 2011).

Calaça, et al., (2017), realizaram um estudo para investigar a eficácia das BAL no tratamento e redução do câncer de cólon em modelo animal, os trabalhos avaliados apresentaram resultados satisfatórios quanto à inibição do câncer de cólon em ratos e camundongos ao utilizarem cepas predominantemente do gênero Lactobacillus. Os artigos analisados mostraram que, o tratamento e o efeito antitumoral com dietas associadas às BAL possuem possibilidade de um tratamento menos invasivo para o câncer de cólon, aumentando assim, a qualidade de vida dos pacientes e ajudando na rotina médica.

\subsection{Intolerância à lactose}

Os probióticos, têm sido usados como mecanismo coadjuvante no tratamento de portadores de intolerância à lactose, a fim de melhorar o quadro clínico ou a retardar a progressão dos sintomas. Trata-se de uma terapia ainda pouco estudada, já que os dados obtidos são recentes (Pinto et al., 2018).

As pessoas com intolerância a lactose, toleram melhor lactose presente no iogurte do que à lactose presente no leite, devido à presença de bactérias no iogurte, especialmente Lactobacillus acidophilus, que contribui para a digestão e absorção de lactose (Suchy et al., 2010; Repa et al., 2015). A presença de Lactobacillus bulgaricus e Streptococcus thermophilus diminuem a intolerância à lactose devido a capacidade que tem em produzir a enzima lactase (Montes et al., 1995; Rul et al., 2011). Adicionalmente, em outro estudo, verificou-se que o consumo de leite contendo Bifidobacteriumlongum resultou em uma menor produção de hidrogênio e sintomas de flatulência, quando comparado com o consumo de leite pasteurizado como controle (Andrade \& Borges, 2009).

\subsection{Desempenho zootécnico}

A nutrição é utilizada como uma estratégia para aumentar os índices de produção, e os promotores de crescimento podem contribuir para melhorar o desempenho dos animais em crescimento. O uso de antibióticos é uma prática que vem sendo abolida, devido a exigência dos consumidores devido ao risco de resíduos destes medicamentos nos produtos de origem animal. Com isso os probióticos vem sendo utilizados como produtos alternativos para melhoria no desempenho zootécnico dos animais (Alves et al., 2004).

Os probióticos proporcionam benefícios positivos na microbiota intestinal, auxiliando no crescimento de bactérias da microbiota encontrada no intestino, o que vem a proporcionar equilíbrio ao local; previne o surgimento de infecções intestinais, evitando que as bactérias patogênicas colonizem os sítios de ligação no trato intestinal; instigam a imunidade local aumentando a síntese de IgA secretada no intestino, está por sua vez impede que bactérias patogênicas venham a povoar o meio; diminuem as reações inflamatórias, protegendo o intestino da invasão de agentes patogênicos, evitando assim o surgimento de enterites; e realizam o ajuste da motilidade intestinal, facilitando a absorção de nutrientes (Ferreira et al., 1998).

$\mathrm{Na}$ aquicultura o uso de probióticos está aumentando devido à preocupação pelo uso de práticas menos agressivas ao ambiente, reduzir riscos de perdas na produção em função de doenças e para suprimir ou competir com organismos patogênicos (Moriarty, 1998; Kesarcodi-Watson et al., 2008; Liu et al., 2014). O gênero de bactérias ácido lácticas mais utilizado é o Lactobacillus, na qual a espécie L. plantarum é um exemplo de sucesso no emprego de bactérias lácticas como probiótico em organismos aquáticos (Vine et al., 2006). 
Penha et al., (2009) realizaram um estudo sobre a ação dos probióticos frente ao cortisol sérico e o ganho de peso em bovinos. Nesse estudo foram utilizados 40 bovinos da raça nelore em sistema de pastejo extensivo. Um grupo recebeu probiótico composto por Lactobacillus acidophilus, Enterococcus faecium, Bifidobacterium thermophilum e Bifidobacterium longum, já o outro grupo não recebeu nenhum tipo de probiótico. O grupo tratado com probiótico obteve ganho de peso vivo durante os primeiros 75 dias de experimento e manteve a dosagem sérica de cortisol próximo ao nível basal, diferente do grupo controle que no dia $150^{\circ}$ apresentou aumento significativo do cortisol sérico. Estes resultados indicam que a administração de probiótico eleva o peso dos animais nos primeiros 75 dias e diminui a concentração sérica de cortisol no $150^{\circ}$ dia, mesmo quando os animais se encontram frequentemente submetidos a movimentação e a prática da pesagem no curral.

Em estudo sobre o efeito da adição de probióticos na quantidade e qualidade de leite de vacas da raça Girolando no bioma do cerrado, foi possível observar que o emprego de probióticos (Lactobacillus acidophilus, Streptococus faecium e bacillus subtilis) apresenta um grande potencial para a aumentar a lucratividade da pecuária leiteira, levando a um aumento da quantidade e da qualidade do leite em vacas Girolando. A melhoria na qualidade se deve a redução da contagem de células somáticas (CCS) no leite do experimento, o que é condizente com os efeitos do probiótico no sistema imune dos animais (Magnabosco et al., 2010).

Segundo Hayakawa et al., (2016) os efeitos mais significativos dos probióticos na microbiota intestinal e nos animais hospedeiros ocorrem quando são incluídos nas dietas durante períodos particularmente estressantes, como o desmame e / ou no início do período de lactação. Seu trabalho, sobre a administração dietética de probióticos para porcas e / ou seus neonatos em busca da melhora do desempenho reprodutivo e incidência de diarreia pós-desmame, mostrou que ocorreu uma melhora no retorno ao estro pela administração de probióticos a porcas. Além disso, o consumo de ração das porcas administradas com probióticos foi maior do que o das porcas controle durante o período tardio de lactação, e incidência de diarreia pós-desmame e o desempenho de crescimento foram melhorados pela administração de probióticos aos recém-nascidos.

Freitas (2008) realizou um experimento sobre o efeito de BAL sobre o ganho de peso de leitões na maternidade, onde um grupo de leitões logo após o parto e antes da mamada do colostro recebiam o probiótico e outro grupo recebia água destilada (placebo). $\mathrm{O}$ ganho de peso médio diário dos leitões que receberam o probiótico foi bastante evidente aos 7 e 14 dias de idade, em comparação com o grupo que recebeu placebo, mostrando que hospedeiros com microbiota e estável e saudável conseguem aproveitar mais os nutrientes.

Ao avaliar o uso de um probiótico como alternativa estratégica para substituição de promotores de crescimento nas dietas de frango de corte, foram utilizados Lactobacillus acidophilus; Streptococcus faecium e Bifidobacteriumbifidum. Onde o grupo tratado com probiótico apresentou menor consumo de ração e melhor conversão alimentar. Permitindo verificar significativamente que o probiótico utilizado no experimento pode ser usado como uma alternativa estratégica para a substituição dos promotores de crescimento em aves de corte (Rigobelo et al., 2011).

Outro trabalho realizado com frangos de corte, mostrou que os probióticos (Streptococcus faecium, Lactobacillus acidophilus, Saccharomyces cerevisiae, Bacillus subtilis) podem ser empregados juntos com a monensina sódica (agente anticoccidiano) e a avilamicina (promotor de crescimento). Frangos (1 a 42 dias de idade) alimentados, com rações adicionadas desses compostos, apresentaram uma menor mortalidade em comparação aos que receberam a ração-controle (Faria et al., 2009). De acordo os resultados apresentados por Jahromi, et al. (2015), Aves que receberam probiótico apresentaram peso corporal e ganho de peso finais significativamente melhores em comparação com as aves do grupo controle. Além disso, houve melhora na conversão alimentar. 


\subsection{Culturas starter e Biopreservação}

A procura de alimentos seguros, que não recorram à adição excessiva de conservantes químicos, aumentou de forma significativa nos últimos anos. Observando-se o desenvolvimento de novos produtos e o conceito de biopreservação aplicado aos alimentos adquiriu uma grande importância tanto para as indústrias quanto para os consumidores (STILES, 1996; KRÖCKEL, 2013). A aplicação de culturas bacterianas nos processos de produção de alimentos ocorre há muitos anos, permitindo um maior controle da qualidade em nível industrial, seja em relação ao tempo de fabricação dos produtos ou pela padronização dos mesmos (sabor, cor, aroma), certificando assim características finais homogêneas nos produtos ( Zeuthen, 2007; Bernardi \& Contreras-Castillo, 2010).

Culturas starter pode ser definidas como preparações que contêm micro-organismos vivos ou em estado latente que se desenvolvem pela fermentação de um determinado substrato presente no meio (Hammes \& Hertel, 1998).

A biopreservação pode ser definida como o uso de microbiota competitiva para o controle de micro-organismos deteriorantes e patogênicos (Krockel, 2013). Lücke (2000) referiu que culturas bioprotetoras são culturas antagonistas que inibem patógenos e aumentam a vida útil, participando ainda nas propriedades sensórias do produto.

Para produção de embutidos cárneos fermentados os micro-organismos utilizados são, normalmente, divididos em dois grupos: bactérias láticas, responsáveis pelo processo de acidificação via glicólise e os micro-organismos que desenvolvem o aroma, o flavor e a cor, frequentemente capazes de reduzir nitrato a nitrito (Jessen, 1995; Fernandéz et al., 2000, Simonová et al., 2006). Sua utilização não envolve apenas a questão de higiene, mas visa também assegurar uma proteólise e uma lipólise mais intensa, e um perfil mais complexo de componentes voláteis (Di Cagno et al., 2008).

Algumas culturas, em ação conjunta com os sais de cura (nitrato e nitrito de sódio), podem inibir o desenvolvimento de micro-organismos indesejáveis, como Staphylococcus aureus e coliformes, em embutidos cárneos fermentados (Spricigo \& Pianovsky, 2005). Geralmente, as bactérias láticas utilizadas como culturas starter pertencem aos gêneros Lactobacillus e Pediococcus. As espécies $L$. sakei e $L$. curvatus são os micro-organismos psicrotróficos mais competitivos no ambiente. $L$. plantarum e Pediococcus spp. são mesófilos e, portanto, têm seu desenvolvimento favorecido em fermentação com temperatura entre 30 e $35^{\circ} \mathrm{C}$ (Toldrá et al., 2001).

O papel principal desenvolvido pela bactéria lática está relacionado com o metabolismo do carboidrato que resulta na acidificação da massa cárnea, com formação de ácido lático e redução do pH, assegurando a estabilidade higiênica do produto, transmitindo características ácidas ao sabor, causando coagulação das proteínas da carne (em pH de 5,4 a 5,5) e reduzindo a capacidade de retenção de água, fato que, consequentemente, facilita a secagem e aumenta a consistência do produto; além disso contribui para o desenvolvimento da cor vermelha desejável característica em produtos curados, pelo favorecimento da reação do óxido nítrico com a mioglobina (Toldrá et al., 2001). Porém espécies heterofermentativos que produzem outros compostos além do ácido lático, tais como o ácido acético, o ácido fórmico e o gás carbônico, não são desejáveis, pois, o principal defeito causado pelo gás carbônico é a formação de cavidades no interior dos embutidos (Kunz, 1986).

Há uma tendência atual para usar linhagens "selvagens" isoladas de alimentos fermentados tradicionais para serem usadas como culturas starters em processos de fermentação, pois divergem fortemente de cepas utilizadas como iniciadoras em termos de diversidade de atividades metabólicas sendo bem adaptadas para o crescimento de forma rápida e eficiente, garantindo assim, uma cultura bem selecionada, adaptada e eficaz para a elaboração de produtos fermentáveis de excelente qualidade (Paulo, 2010).

Schmitt (2017), avaliou a aceitação do salame tipo italiano produzido com adição de culturas iniciadoras, onde o primeiro lote não continha micro-organismos adicionados à massa, denominado de controle, o segundo possuía culturas iniciadoras comerciais (Staphylococcuscarnosus e Lactobacillus pentosaceus) e o terceiro continha culturas iniciadoras a partir de leite fermentado (Lactobacillus caseiShirota). A adição de culturas iniciadoras comerciais e culturas a partir de leite 
fermentado apresentaram um comportamento físico-químico semelhante quanto ao $\mathrm{pH}$ e perda de massa, sem prejuízo das características sensoriais. $\mathrm{Na}$ análise sensorial foi observado, uma melhor aceitação dos produtos fermentados com a cultura iniciadora Lactobacillus caseiShirota, mostrando que a cultura iniciadora possui potencial para substituir culturas comerciais, uma vez que as características sensoriais oferecidas ao alimento foram bem aceitas pelos consumidores.

As enzimas proteolíticas de BAL possuem um importante papel na degradação de peptídeos e da caseína, levando a produção de aminoácidos livres, que são contribuintes diretos para os gostos básicos de produtos como o queijo e contribuintes indiretos para o seu sabor, uma vez que são precursores de outras reações catabólicas, dando origem a compostos voláteis de aroma (Irigoyen et al., 2007).

O queijo coalho é um tradicional produto do nordeste brasileiro e é produzido principalmente a partir de leite cru, porém, para estar de acordo com os requisitos das Normas Brasileiras (Brasil, 1996), o leite para este queijo necessita ser pasteurizado. Este tratamento térmico reduz a população microbiana endógena do leite, provocando alterações nas características sensoriais dos queijos. Com isso, para superar essa limitação, existe uma demanda para o desenvolvimento de culturas autóctones específicas para queijos tradicionais que permitem a padronização da segurança e qualidade do produto, sem alterar as suas propriedades (Dolci et al., 2008).

A formação do aroma em leite fermentado é resultado dos metabólitos produzidos por culturas lácticas (starters) ou do próprio catabolismo da lactose, tendo o ácido láctico como produto (Resa et al., 2007). Além disso, outros produtos também podem surgir e são diretamente responsáveis pela formação do sabor e aroma dos leites fermentados, como por exemplo, 2,3butanodiona, acetaldeído, peptídeos, acetona, etanol, acetato e outros (Amiot, 1991; Bonczar et al., 2002). Os principais produtos da fermentação do leite são compostos orgânicos, tais como ácidos não voláteis (ácidos pirúvico ou láctico), ácidos voláteis (ácidos acético, fórmico e propiônico), compostos carbonílicos (acetona, acetaldeído, 3-hidróxi-butanona e 2,3butanediona) (Cheng, 2010).

Magalhães et al., (2017) realizaram uma pesquisa para determinar o perfil de compostos voláteis de culturas lácticas de seis linhagens de Lactobacillus rhamnosus de queijo de coalho artesanal com potencial para o desenvolvimento de uma cultura láctica que possa permitir a fabricação de queijo tipo coalho a partir de leite pasteurizado. Os compostos voláteis foram isolados por micro extração em fase sólida, separados e identificados por espectrometria de massas (GC-MS) e cromatografia a gás. As culturas lácticas de Lactobacillus rhamnosus produziram muitos dos compostos voláteis importantes para o aroma do leite fermentado, porém, produziram também, ácido acético. Com isso, foi preciso mais um estudo e acompanhamento com análise sensorial para observar se a produção do ácido acético interfere de forma negativa no sabor do produto.

Chagas (2012) estudou a influência de Streptococcus thermophilus produtor de EPS em iogurte natural com baixo teor de lactose. Ao analisar os dados foi possível perceber que o efeito negativo que a hidrólise da lactose causava na viscosidade do iogurte podia ser revertido usando culturas láticas produtoras de EPS. O EPS mostrou-se um excelente agente espessante e geleificante, além de melhorar a capacidade de retenção de água, pois a sinérese é outro problema ligado a produção de iogurte com lactose hidrolisada, uma vez que estes apresentam uma maior sinérese quando comparados a formulação com lactose íntegra.

\section{Conclusão}

As bactérias ácido láticas são micro-organismos isolados a partir de meios ricos em nutrientes, caracterizadas de acordo com sua forma e perfil bioquímico, podendo ser utilizados métodos mais rápidos e precisos de identificação, como os métodos moleculares. São de grande importância para a indústria, conferindo características sensoriais aos produtos, como aroma, sabor e consistência, além, de conferir uma proteção e aumento da vida útil dos alimentos. As BAL também possuem 
papel importante para os animais melhorando a sanidade e produção, e participação em saúde pública, através de seus efeitos probióticos.

Diante do exposto é notória a importância das bactérias ácido láticas tanto para indústria, quanto para saúde pública e para a pecuária, demonstrando a necessidade de se realizar ainda mais estudos sobre os seus potenciais de utilização.

\section{Referências}

Anvisa. Agência nacional de vigilância sanitária. (2002). Resolução de Diretoria Colegiada - RDC nº 02 , de 07 de janeiro de 2002 . Aprova o Regulamento Técnico de Substâncias Bioativas e Probióticos Isolados com Alegação de Propriedades Funcionais e/ou de Saúde. Diário Oficial da República Federativa do Brasil, Brasília.

Almeida, L. E., Genaro, S. G., Geroti, T. C., Galina, N. F., Giuffrida, R., \& Pardo, P. E. (2012). Efeito do probiótico na resposta imune humoral em bovinos. Colloquium Agrariae, 8 (1), 26-35.

Alves, J. B., Isepon, O. J., \& Bergamashine, A. F. (2004). Efeitos de aditivos alimentares enzimáticos contendo probiótico no desempenho de bovinos Guserá em confinamento. In: reunião anual da sociedade brasileira de zootecnia, Campo Grande. Anais. Campo Grande: Sociedade Brasileira de Zootecnia.

Amiot, J. (1991). Ciencia y tecnologia de laleche: principios e aplicaciones. Zaragoza: Acribia, 547.

Andrade, S., \& Borges, N. (2009). Effect of fermented milk containing Lactobacillus acidophilus and Bifidobacterium longum on plasma lipids of women with normal or moderately elevated cholesterol. Journal of Dairy Research. 4,469- 474.

Angelakis, E., Million, M., Henry, M., \& Raoult, D. (2011). Rapid and Accurate Bacterial Identification in Probiotics and Yoghurts by MALDI-TOF Mass Spectrometry. Journal of Food Science. 6, (8).

Antônio, M. B., \& Borelli, B. M. (2020). A importância das bactérias ácido láticas na segurança e qualidade dos queijos minas artesanais. Rev. Inst. Laticínios Cândido Tostes, Juiz de Fora, 75 (3), 204-221.

Arqués, J. L., Rodríguez, E., Nuñes, M., \& Medina, M. (2011). Combined effect of reuterin and lactic acid bacteria bacteriocins on the inactivation of foodborne pathogens in Milk. Food Control, Oxford, 22, 457-461.

Arruda, P. H. E., Madson, D. M., Ramirez, A., Rowe, E. W., \& Songer, J. G. (2016). Bacterial probiotics as an aid in the control of Clostridium difficile disease in neonatal pigs. Journal Canadian Vet, 57,183-188.

Bernardi, S., Golineli, B. B., \& Contreras-Castillo, C. J. (2010). Aspectos da aplicação de culturas starter na produção de embutidos cárneos fermentados. Brazilian Journal of Food Technology. 2, 133 - 140.

Bittencourt, L. C. (2006). Efeitos da utilização de probiótico sobre parâmetros da resposta imune, hematológicos e de desempenho de frangos de corte. Dissertação. Pós-graduação em nutrição animal. Universidade de São Paulo.

Bonczar, G., Wszolek, M., \& Siuta, A. (2002). The effects of certain factors on the properties of yoghurt made from ewe's milk. Food Chemistry, 79, 85-91.

Bostan, K., Alcay, A. U., Yalçin, S., Vapur, U. E., \& Nizamlioglu, M. (2017). Identification and characterization of lactic acid bacteria isolated from traditional cone yoghurt. Food Sci Biotechnol.

Bouchard, D. S., Seridan, B., Saraoui, T., Rault, L., Germon, P., Moreno, C. G., Macias, F. M. E. N., Baud, D., François, P., Chuat, V., Chain, F.,Langella, P., Nicoli, J., Loir, Y. L., \& Even, S. (2015). Lactic acid bacteriaI isolated from bovine mammary microbiota: Potential allies against bovine mastitis. Journal plos one, $1-18$.

Brasil. (1996). Ministério da Agricultura, do Abastecimento e da Reforma Agrária. Portaria no 146, de 07 de março de 1996 . Aprova regulamentos técnicos de identidade e qualidade dos produtos lácteos. Diário Oficial [da] República Federativa do Brasil, Brasília, DF, Seção 1, p. 3977. Disponível em: $<$ http://extranet.agricultura.gov.br/sislegisconsulta/consultarLegislacao.do?operacao=visualizar\&id=1218>.

Busanello, M., Pozza, M. S. S., Barros, P., Chambo, A. P. S., \& Eckstein, I. I. (2012). Probióticos, seus modos de ação e a produção animal. Scientia Agraria Paranaensis, 11 (4), 14-24.

Calaça, P. R. A., Bezerra, R. P., Porto, A. L. F., \& Cavalcanti, M. T. H. (2017). Podem as bactérias ácido lácticas probióticas apresentarem efeito antitumoral em modelo animal de câncer de cólon? Uma revisão da literatura. Pesquisa Veterinária Brasileira. 6, 587-592.

Carvalho, J. D. G. (2007). Caracterização da microbiota lática isolada de queijo de Coalho artesanal produzido no Ceará e de suas propriedades tecnológicas. 154 f. Tese (Doutorado em Tecnologia de Alimentos) Campinas: Departamento de Tecnologia de Alimentos, Universidade Estadual de Campinas. São Paulo.

Cerning, J., Bouillanne, C., Landon, M., \& Desmazeaud, Y. (1992). Isolation and Characterization of Exopolysaccharides from Slime-Forming Mesophilic Lactic Acid Bacteria. JournalDairy Science. 75, 692-699.

Chagas, L. M. (2012). Influência de Streptococcus thermophilus produtor de exopolissacarídeos em iogurte natural com baixo teor de lactose. 48f. Tese (Mestre em Ciência e Tecnologia do Leite) - Universidade Norte do Paraná, Londrina.

Chammas, G., Saliba, R., Corrieu, G., \& Béal, C. (2006). Characterisation of lactic acid bacteria isolated from fermented milk "laban". International Journal of Food Microbiology. 110, 52-61. 
Chao, S. H., Tomii, Y., Sasamoto, M., Fujimoto, J., Tsai, Y.C., \& Watanabe, K. (2008). Lactobacillus capillatus sp. nov., a motile Lactobacillus species isolated from stinky tofu brine. International Journal of Systematic and Evolutionary Microbiology.58, 2555-2559.

Cheng, h. (2010). Volatile flavor compounds in yogurt: a review. Critical Reviews in Food Science and Nutrition. 50, $938-950$.

Collins, J. K., Thornton, G., \& Sullivan, G. O. (1998). Selection of probiotic strains for human applications. International Dairy Journal. 8, 487-490.

Coppola, M. M., \& Turnes, C. G. (2004). Probióticos e resposta imune. Microbiologia. Cienc. Rural 34 (4).

Costa, A. C. C. C. (2016). Isolamento de bactérias láticas produtoras de bacteriocinas e avaliação de sua atividade frente a patógenos alimentares em sistema de bioconservação de produto lácteo. 58 f. Dissertação (Mestrado em Ciência e Tecnologia de Alimentos) - Universidade Federal de Goiás, Goiânia.

Dec, M., Puchalski, A., Urban-Chmiel, R., \& Wernicki, A. (2016). 16S-ARDRA and MALDI-TOF mass spectrometry as tools for identification of Lactobacillus bacteria isolated from poultry.

Deng, Q., Odhiambo, J. F., Farooq, U., Lam, T., Dunn, S. M., \& Ametaj, B. N. (2016). Intravaginal probiotics modulated metabolic status and improved milk production and composition of transition dairy cows. J. Anim. Sci. 94:760-770.

Di Cagno, R., Lòpez, C. C., Tofalo, R., Gallo, G., De Angelis, M., Paparella, A., Hammes, W. P., \& Gobbetti, M. (2008). Comparison of the compositional, microbiological, biochemical and volatile profile characteristics of three Italian PDO fermented sausages. Meat Science, Amsterdam, 2, 224-235.

Dietrich, C. G., Kottmann, T., \& Alavi, M. (2014). Commercially available probiotic drinks containing Lactobacillus casei DN-114001 reduce antibioticassociated diarrhea. World J Gastroenterol. 42, 15837-15844.

Dolci, P., Alessandria, V., Zeppa, G., Rantsiou, K., \& Cocolin, L. (2008). Microbiological characterization of artisanal Raschera PDO cheese: analysis of its indigenous lactic acid bacteria. Food Microbiology. 25, 392-399.

European Food Safety Authority. (2015). Statement on the update of the list of QPS recommended biological agents intentionally added to food or feed as notified to EFSA 3: Suitability of taxonomic units notified to EFSA until September 2015. EFSA Journal. 12, 1-25.

Embrapa. Empresa Brasileira de Pesquisa Agropecuária. (2009). Documento 124-Microbiota lática de queijos artesanais, p. 9-22.

Espeche, M. C., Pellegrino, M., Frola, I., Larriestra, A., Mbogni, C., \& Nader-Macías, M. E. F. (2012). Lactic acid bacteria from raw milk as potentially beneficial strains to prevent bovine mastitis. Anaerobe 18, $103-109$.

Faria, D. E., Henrique, A. P. F., Neto, R. F., Medeiros, A. A., Junqueira, O. M., \& Faria Filho, D. E. (2009). Alternativas ao uso de antibióticos como promotores de crescimento para frangos de corte: 1. Probióticos. Ciênc. Anim. Brasil., 10 (1), 18-28.

(Fao/Who). Food and Agricultural Organization/World Health Organization. (2002). Guidelines for the evaluation of probiotics in food. London: FAO/WHO.

Fernández, M., Ordóñez, J. A., Bruna, J. M., Herranz, B., \& Hoz, L. (2000). Accelerated ripening of dry fermented sausages. Trends in Food Science \& Technology, Oxford. 6, 201-209.

Ferreira, A. J. P., Ferreira, C. A., Petrella Neto, R, Oliveira, D. R., Nuremberger Júnior, R., \& Lopes, V. C. B. A. (1998). Probiotics: benefits and efficiency in poultry production. Arquivos do Instituto Biológico, 65, 139-149.

Ferreira, A. P., \& Astolfi-Ferreira, C. S. (2006). Medidas inespecíficas para o controle bacteriano. In: SIMPÓSIO BRASIL SUL DE AVICULTURA, Chapecó, Anais... Chapecó, p.56-66.

Ferreira, L. A. (2010). Avaliação da vacinação antirrábica e da suplementação com probiótico na resposta imune humoral em bovinos. Mestrado em ciência animal. Universidade do Oeste Paulista - Presidente Prudente.

Forsythe, S.J. (2002). Microbiologia da Segurança Alimentar. A Flora Microbiana dos Alimentos: Alimentos fermentados. Artmed Editora. $132-147$.

Franco, B. D. G de M., \& Landgraf, M. (2008). Micro-organismos patogênicos de importância em alimentos. In: Microbiologia dos alimentos. São Paulo: Atheneu. 4, 48-60.

Freitas, M. C. (2008). Efeito da administração de bactérias ácido láticas sobre o ganho de peso de leitões na maternidade. 49f. Tese (Mestrado em medicina veterinária) - Faculdade de Medicina Veterinária e Zootecnia, Pirassununga, São Paulo.

Furtado, D. N., Todorov, S. D., Landgraf, M., Destro, M. T., \& Franco, B. D. G. M. (2015). Bacteriocinogenic Lactococcus lactis subs. lactis DF04Mi isolated from goat milk: Application in the control of Listeria monocytogenes in fresh Minas-type goat cheese. Brazilian Journal of Microbiology, São Paulo, 46 (1), 201-206.

Garcia, G. R. (2006). Inhibition of the growth of pathogenic bacteria by Lactobacillus acidophilus. Revista Portuguesa de Ciências Veterinárias. 101, 263 268.

Giorgetti, G., Brandimarte, G., Fabiocchi, F., Ricci, S., \& Flamini, P. (2015). Interactions between Innate Immunity, Microbiota, and Probiotics. Journal of Immunology Research.

Greppi, A., Ferrocino, I., La Storia, A., Rantsiou, K., Ercolini, D., \& Cocolin, L. (2015). Monitoring of the microbiota of fermented sausages by culture independent rRNA-based approaches. Internation Journal of Food Microbiology, 212, 67-75.

Gurtler V. \& Stanisich V. A. (1996). New approaches to typing and identification of bacteria using the 16S-23S rDNA spacer region. Microbiology 142:3-16.

Hammes, W. P., \& Hertel, C. (1998). New Developments in Meat Starter Cultutres. Meat Science. 1, S125 - S138. 
Hassan, A. N., \& Frank, J. F. (2001). Starter cultures and their use. In: Marth, E. H., Steele, J. L. Applied Dairy Microbiology, (2a ed.), Marcel Decker.

Hayakawa, T., Masuda, T., Kurosawa, D., \& Tsukahara, T. (2016). Dietary administration of probiotics to sows and/or their neonates improves the reproductive performance, ncidence of post-weaning diarrhea and histopathological parameters in the intestine of weaned piglets. Animal Science Journal, 87, 1501-1510.

Heredia-Castro, P. Y., Hérnández-Mendoza, A., González-Córdova, A. F., \& Vallejo-Cordoba, B. (2017). Bacteriocinas de bactérias ácido lácticas: Mecanismo de acción y actividad antimicrobiana contra patógenos en quesos.

Inês, A., Tenreiro, T., Tenreiro, R., \& Faia, M. (2008). As Bactérias do Ácido Láctico do Vinho. 81-96.

Irigoyen, A., Ortigosa, M., Juansaras, I., Oneca, M., \& Torre, P. (2007). Influence of an adjunct culture of Lactobacillus on the free amino acids and volatile compounds in a Roncal-type ewe's-milk cheese. Food Chemistry. 100, 71-80.

Isli. (2013). Probióticos, prebióticos e a microbiota intestinal. International Life Sciences Institute. 1-30.

Ivey, K. L., Hodgson, J. M., Kerr, D. A., Thompson, P. L., Stojceski, B, \& Prince, R. L. (2015). The effect of yoghurt and its probiotics on blood pressure and serum lipid profile, a randomised controlled trial.Nutrition, Metabolism e Cardiovascular Diseases, $25,46-51$.

Jahromi, M. F., Altaher, Y. W., Shokryazdan, P., Ebrahimi, R., Edrahimi, M., Idrus, Z., Tufarelli, V., \& Liang, J. B. (2015). Dietary supplementation of a mixture of Lactobacillus strains enhances performance of broiler chickens raised under heat stress conditions. International Journal of Biometeorolog, 60, 1099-1110.

Jessen, B. (1995). Starter cultures for meat fermentation. In: Campbell-Platt, G., Cook, P. E. Fermented Meats. London: Blackie Acad Prof. 6, 130-159.

Kesarcodi-Watson, A., et al. (2008). Probiotics in aquaculture: the need, principles and mechanisms of action and screening processes. Aquaculture, 274, 1-14.

Kröckel, L. (2013). The role of Latic Acid Bacteria in Safety and Flavour Development of Meat and Meat Products (2013). In: Lactic Acid Bacteria - R \& D for food, Health and Livestock Purposes, 670, Kongo, M. (Ed.), 129 - 152.

Kunz, B. (1986). Cultivo de microrganismos para la producción de alimentos: obtención, aplicaciones e investigación. Zaragoza: Acribia. 123.

Laranja, D. C. (2016). Atividade antimicrobiana da nisina em presunto cozido sobre Listeria monocytogenes e bactérias ácido láticas. Universidade Federal do Rio Grande do Sul. Porto Alegre.

Lebeer S., Vanderleyden J., \& de Keersmaecker S. C. J. (2010). Host interactions of probiotic bacterial surface molecules: comparison with commensals and pathogens. Nature Reviews Microbiology. 8, $171-184$.

Lebeer, S., Vanderleyden, J., \& de Keersmaecker, S. C. J. (2008). Genes and molecules of lactobacilli supporting probiotic action. Microb. Mol. Biol. Rev. 4, $728-764$.

Lee, Y. K., Nomoto, K., Salminen, S. et al. (1999). Handbook of probiotics. Wiley.

Lerayer, A. L. S., Marasca, E. T. G., Moreno, I., \& Vialta, A. (2009). Culturas lácticas e probióticas: Identificação, classificação, detecção e aplicação tecnológica. In: Oliveira, M. N. Tecnologia de produtos lácteos funcionais. São Paulo: Editora Atheneu, 125-186.

Lima, C., Lima, L., Cerqueira, M., Ferreira, E., \& Rosa, C. (2009). Bactérias do ácido láctico e leveduras associadas com o queijo-de-minas artesanal produzido na região da Serra do Salitre, Minas Gerais. Arquivo Brasileiro Medicina Veterinária e Zootecnia. 1, $266-272$.

Liu, H., et al. (2014). Oral administration of Lactobacillus fermentum I5007 favors intestinal development and alters the intestinal microbiota in formula-fed piglets. Journal of Agriculture Food Chemical, 62, 860-866.

Madigan M. T., Martinko J. M., Dunlap P. V., \& Clark D. P. (2010). Microbiologia de Brock. (12a ed.), Artmed.

Magalhães, H. C. R., Bruno, L. M., Garruti D, S., \& Rodrigues, T. C. (2017). Compostos voláteis de leites fermentados por linhagens de Lactobacillus rhamnosus. Embrapa. Boletim de pesquisa e desenvolvimento.

Magnabosco, C. U., Carnevalli, R. A., Sainz, R. D., Filgueiras, A. E., \& Mamede, M. M. S. (2010). Efeito da adição de pobióticos e prebióticos na quantidade e qualidade do leite de vacas da raça Girolando no bioma cerrado. Comunicado técnico 165. Embrapa. Planaltina - DF.

Mizock, B. A. (2015). Probiotics. DisEASE-A- Month, 61, 259-290.

Montes, R. G., Bayless, T. M., Saavedra, J. M., \& Perman, J. A. (1995). Effect of milks inoculated with Lactobacillus acidophilus or a yogurt starter culture in lactose-maldigesting children. Journal of Dairy Science. 8, 1657-1664.

Moreira J. L. S., Mota R. M., Horta M. F. et. al. (2005). Identification to the species level of Lactobacillus isolated in probiotic prospecting studies of human, animal or food origin by $16 \mathrm{~S}-23 \mathrm{~S}$ rRNA restriction profiling. BMC Microbiology, 5:15

Moriarty, D. J. W. (1998). Control of luminous Vibrio species in penaeid aquaculture ponds. Aquaculture, 164, $351-358$.

Nagpal, R., Kumar, A., \& Kumar, M. (2012). Probiotics, their health benefits and applications for developing healthier foods: a review. FEMS Microbiology. $334,1-15$.

Nacef. M., Chevalier, M., Chollet, S., Drider, D., \& Flahaut C. (2016). MALDI-TOF mass spectrometry for the identification of lactic acid bacteria isolated from a French cheese: The Maroilles. Internation Journal of Food Microbiology.

Nielsen, D. S., Schillinger, U., Franz, C. M. P., Bresciani, J., Awua, W. A., Holzapfel, W. H., \& Jakobson, M. (2007). Lactobacillus ghanensis sp. Nov., a motile lactic acid bacterium isolated from Ghanaian cocoa fermentations. International Journal of Systemic Evolutionary Microbiology, 7, $1468-1472$. 
Nixon, A. F., Cunningham, S. J., Cohen, H. W., \& Crain, E. F. (2012). The effect of Lactobacillus GG on acute diarrheal illness in the pediatric emergency department. Pediatric Emergency Care. 10, 1048-1051.

Oelschlaeger, T. A. (2010). Mechanisms of probiotic actions - a review. International Journal of Medical Microbiology. 300,57 - 62.

Ogaki, M. B., Furlaneto, M. C., \& Maia, L. F. (2015). Revisão: aspectos gerais das bacteriocinas. Brazilian Journal of Food Technology, 18 (4), $267-276$.

Oshiro, E. (2015). Prebiótico e probiótico na dieta de tilápia-do-Nilo: perfil hematológico, resposta imune inata e desempenho zootécnico. 40 f. Dissertação (mestrado) - Universidade Estadual Paulista Júlio de Mesquita Filho, Centro de Aquicultura de Jaboticabal.

Pant, N., Marcotte, H., Hermans, P., Bezemer, S., Frenken, L., Johansen, K., \& Hammarström, L. (2011). Lactobacilli producing bispecific llama-derived antirotavirus proteins in vivo for rotavirus-induced diarrhea. Future Microbiology. 5, 583-593.

Patel, S., Shukla, R., \& Goyal, A. (2015). Probiotics in valorization of innate immunity across various animal models. Journal of Functional Foods 14, 549561.

Paulo, E. M. (2010). Produção de exopolissacarídeos (EPS) por bactérias láticas visando microencapsulação de Lactobacillus acidophilus La-5 pelo processo de Spray drying. Tese 212f. (Doutorado em Biotecnologia), Departamento de Ciências Biológicas, Universidade Estadual de Feira de Santana, Feira de Santana.

Pebmed. (2020). MALDI-TOF-MS: método proteômico para a identificação rápida e eficaz. Site PEBMED.

Penha, L. A. C. (2009). Efeito da suplementação com probiótico no cortisol sérico e no ganho de peso em bovinos. 2009. 49f. Tese (Mestre em Ciência Animal) - Universidade do Oeste Paulista, São Paulo.

Pinto, L. P. S., Almeida, P. C, Baracho, M, \& Simioni P. U. (2018). O uso de probióticos para o tratamento do quadro de intolerância à lactose. Ciência \& Inovação, 2 (1).

Pimentel, T. C. (2011). Probióticos a Benefícios à Saúde. Revista Saúde e Pesquisa. 1, 101-107.

Prado, C. S., Santos, W. L. M., Carvalho, C. R., Moreira, E. C., \& Costa, J. O. (2000). Atividade antimicrobiana de bactérias lácticas de embutidos curados frente a Listeria monocytogenes. Arquivo Brasileiro de Medicina Veterinária e Zootecnia, vol 52, n.4, Belo Horizonte.

Pugliesi, C. F., Silva, L. S., Silva, R. R. C., Oliveira, R. M., Silva, R. P., \& Gomes, T. K. C. (2014). Probióticos e sua ação na saúde do consumidor. Revista de Trabalhos Acadêmicos Universo Recife.

Repa, A., Thanhaeuser, M., Endress, D., Weber, M., Kreissl, A., Binder, C., Berger, A., \& Haiden, N. (2015). Probiotics (Lactobacillus acidophilus and Bifidobacterium infantis) prevent NEC in VLBW infants fed breast milk but not formula [corrected]. Pediatric Research. 2, 381-388.

Resa, P., Bolumar, T., Elvira, L., Pérez, G., \& Espinosa, F. M. (2007). Monitoring of lactic acid fermentation in culture broth using ultrasonic velocity. Journal of Food Engineering, 78, 1083-1091.

Resende, M. F. S., Costa, H. H. S., \& Andrade, E. H. P. (2011). Queijo de minas artesanal da Serra da Canastra: influência da altitude das queijarias nas populações de bactérias ácido lácticas.Arquivo Brasileiro Medicina Veterinária e Zootecnia. 6, 1567-1573.

Rigobelo, E. C., Maluta, R. P., \& Ávila, F. A. (2011). Desempenho de frangos de corte suplementadas com probiótico. ARS Veterinaria. 2, 111-115.

Rocha, A.P. (2013). Uso de butirato de sódio protegido em rações de frangos de corte. Universidade Federal do Recôncavo da Bahia - Centro de Ciências agrárias, ambientais e biológicas. Programa de pós-graduação em ciência animal-Curso de mestrado. Cruz das Almas, Bahia.

Rodríguez, C., Cofré, J. V., Sánchez, M., Fernández, P., Boggiano, G., \& Castro, E. (2011). Lactobacilli isolated from vaginal vault of dairy and meat cows during progesteronic stage of estrous cycle. Anaerobe $17.15-18$.

Rul, F., Ben-Yahia, L., Chegdani, F., Wrzosek, L., Thomas, S., Noordine, M. L., Gitton, C., Cherbuy, C., Langella, P., \& Thomas, M. (2011). Impact of the metabolic activity of Streptococcus thermophilus on the colon epithelium of gnotobiotic rats. The Journal of Biological Chemistry. 12, 10288-10296.

Saarela, M., Mogensen, G., Fonde, R. et al. (2000). Probiotic bacteria: safety, functional and technological properties. Journal of Biotechnology. 84, 197-215.

Sablon E, B. (2000). Contreras and E. Vandamme. Antimicrobial peptides of Lactic Acid Bacteria: Mode of Action, Genetic and Biosynthesis. In Advances in Biochemical Engineering/Biotechnology. [Th. Scheper] Springer-Verlag.

Salminen, S., \& Wright, V. A. (1993). Lactic Acid Bacteria, Marcel Dekker.

Santos, D. S., Calaça, P. R. A., Porto, A. L. F., Souza, P. R. E., \& Cavalcanti, M. T. H. (2019). Caracterização parcial probiótica e molecular de bactérias ácido lácticas isoladas de queijo de coalho da cidade de Arcoverde - Pernambuco. Iniciação Científica CESUMAR - jan./jun., 21 (1), 7-14.

Schmitt, B. (2017). Avaliação sensorial do uso de diferentes culturas iniciadoras na produção de salame tipo italiano do frigorífico Antônio Carlos. 201. 64f. Trabalho Conclusão do Curso (Graduação em Engenharia de Alimentos) - Centro Tecnológico da Universidade Federal de Santa Catarina, Santa Catarina.

Schneider, K. (2016). Aplicação de bactérias láticas com ação antimicrobiana em queijo minas frescal videira. 2016. 91F. Tese (mestrado em Mestrado Medicina Veterinária) - Universidade do oeste de Santa Catarina. Santa Catarina.

Silva K. M. S. (2017). Avaliação comportamental do potencial efeito de bifidobacteriumlactis hn019® em modelo animal de depressão e ansiedade.2017. 47f. Dissertação (Mestre em Ciência e Tecnologia de Leite e Derivados) - UNOPAR, Londrina. 
Research, Society and Development, v. 10, n. 11, e513101119964, 2021

(CC BY 4.0) | ISSN 2525-3409 | DOI: http://dx.doi.org/10.33448/rsd-v10i11.19964

Simonová, M., Strompfová, V., Marciňáková, M., Lauková, A., Vesterlund, S., Moratalla, M. L., Bover-Cid, S., \& Vidal-Carou, C. (2006). Characterization of Staphylococcus xylosuse Staphylococcus carnosus isolated from Slovak meat products. Meat Science, 4, 559-564.

Sornplang, P., \& Piyadeatsoontorn, S. (2016). Probiotic isolates from unconventional sources: a review. Journal of Animal Science and Technology.

Souza, N. B. (2017). Ação antimicrobiana de bacteriocina produzida por Lactobacillus sakei: uma análise de resistência e aplicação em queijo minas frescal. Trabalho de Conclusão de Curso (Graduação em Engenharia de Alimentos) - Universidade Federal do Pampa, Campus Bagé, p. 93, Bagé.

Spricigo, C. B., \& Pianovsky, P. B. (2005). Effect of the use of curing salts and of a starter culture on the sensory and microbiological characteristics of homemade salamis. Brazilian Archives of Biology and Technology. S1, S169-S174.

Stiles, M. E. (1996). Biopreservation by latic acid bacteria. Antonie van Leeuwenhoek, 70, 331 - 345.

Suchy, F. J., Brannon, P. M., Carpenter, T. O., Fernandez, J. R., Gilsanz, V., Gould, J. B., Hall, K., Hui, S. L., Lupton,J., Mennella, J., Miller, N. J., Osganian, S. K., Sellmeyer, D. E., \& Wolf, M. A. (2010). National Institutes of Health Consensus Development Conference: lactose intolerance and health. Annals of Internal Medicine. 12, 792-796.

Sybesma, W., Hugenholtz, J., Vos, W. M., \& Smid, E. J. (2006). Safe use of genetically modified lactic acid bacteria in food. Bridging the gap between consumers, green groups, and industry. Electronic Journal of Biotechnology, 4, 424-448.

Tannock G. W., Tilsala-Timisjarvi A., Rodtong S., Ng J, Munro K., \& Alatossava T. (1999). Identification of Lactobacillus isolates from the gastrointestinal tract, silage, and yoghurt by 16S-23S rRNA gene intergenic spacer region sequence comparisons. Applied Environmental Microbiology, 65:4264-4267.

Teixeira, R. S. (2017). Avaliação do efeito imunomodulador e carrapaticida de micro-organismos probióticos em bovinos da raça Girolando. 2017. 108f. Tese (Doutorado em biotecnologia aplicada) - Escola de Engenharia de Lorena, São Paulo.

Toldrá F., Sanz, Y., Flores, M. Meat Fermentation Technology. In: Hui, Y. H., Nip, W. K., Rogers, R. W., \& Young, O. (2001). Meat Science and Applications. New York: Marcel Dekker Inc., 2001. 537-563.

Vine, N. G., Leukes, W. D., \& Kaiser, H. (2006). Probiotics in marine larviculture. Federation of European Microbiological Societies Microbiology Review, $30,404-427$.

Zabot, S. (2016). Atividade Antimicrobiana de Ácidos Orgânicos e Compostos Clorados sobre Micro-organismos Patogênicos em Carne de Frango. 97 f. Dissertação (Mestrado Profissionalizante em Tecnologia de Alimentos) - Universidade Tecnológica Federal do Paraná. Londrina.

Zeuthen, P. (2007). A historical Perspective of Meat Fermentation. In: Handbook of Meat Processing, 561, Toldrá, F. (Ed.), Wiley-Blackwell, 3 - 8.

Zhang, Z., Xiang, Y., LI. N., Wang, B., Wang, X., Huang L., \& Zheng, Y. (2013). Protective effects of Lactobacillus rhamnosus GG against human rotavirusinduced diarrhoea in a neonatal mouse model. Pathogensand Disease. 3, 184-191. 